To appear in the International Journal of Mathematical Education

in Science and Technology, Vol. 00, No. 00, January 2014, 1-12

\title{
A modified approach to Team-Based Learning in linear algebra courses
}

\author{
Kalman M. Nanes ${ }^{a *}$ a $U M B C$ (The University of Maryland - Baltimore County), Department of \\ Mathematics and Statistics, 1000 Hilltop Circle, Baltimore, MD 21250, USA \\ (Received 00 Month 201X; final version received 00 Month 201X)
}

\begin{abstract}
This paper documents the author's adaptation of team-based learning (TBL), an active learning pedagogy developed by Larry Michaelsen and others, in the linear algebra classroom. The paper discusses the standard components of TBL and the necessary changes to those components for the needs of the course in question. There is also an empirically controlled analysis of the effects of TBL on the student learning experience in the first year of TBL use.
\end{abstract}

Keywords: team-based learning; TBL; quantitative sciences; linear algebra; pedagogy; active learning

\section{Introduction}

As educators in collegiate mathematics, we find ourselves at a crossroads in the development of modern pedagogy. I have found in my classrooms that today's student body includes a significant segment of learners, previously absent from higher education, who do not respond well to traditional lecture-based teaching methods. Current research into lecturing as a pedagogy, while not unequivocal, does provide evidence that alternate pedagogies can help us address this problem ([1-7], and many others). On the other hand, we do not seem, as a community, to have found a widely applicable alternative approach. While active learning methods do exist for the collegiate classroom, most do not seem to be geared towards the study of mathematics and other quantitative sciences. Current presentations on collegiate mathematics education tend to focus only on single activities that can at best engage students on a particular topic for one classroom session. A more holistic approach is required in order to bring active learning into the mathematics classroom in a systemic fashion.

We face many challenges in this task. At my institution, lower level and core mathematics courses have failure rates among the highest of any department at the university. Students are reluctant to actively engage with course material, and do not enter their university careers with effective study habits or time management skills. Attendance in lectures sometimes dwindles to as little as half to two-thirds of the students enrolled. Many students will never open a textbook for a mathematics course, except perhaps to seek out assigned homework problems. At the same time, student population keeps growing at a rate far out of step with faculty growth, meaning that classroom sizes grow larger each year. For me, traditional lectures, while perfectly adequate in some circumstances and for some students, cannot effectively handle these problems. (One could argue that

*Kalman M. Nanes. Email: knanes@umbc.edu 
a strong defense of lectures is their ability to scale to very large classroom sizes. My response is that they do not do so effectively, given the unacceptably large failure rate across these courses at my university. See Section 2.)

Any active learning approach that I adopt must, therefore, accomplish three major tasks. First, the classroom methods must engage with weak students so that students who historically would have failed or withdrawn from mathematics courses can instead pass the class. Second, students must become more self-directed and effective learners, developing study skills and good habits like reading the course text, coming to class, and spending an adequate amount of time on homework. Third, the pedagogical method in question must carry the promise of scaling effectively to large course sizes.

The solution that I attempted beginning in the fall term of 2012 was a modified version of the system known as team-based learning (TBL). TBL is a research-based pedagogy developed by Larry Michaelsen and other instructors over approximately the last 30 years. A reasonably comprehensive introduction can be found in [8]. TBL is not a teaching technique or trick; rather, it is a systemic approach to teaching that is intentionally designed with the end learning goals of the course in mind. I will show below that TBL has the potential to effectively address the issues discussed above.

In this paper, I discuss the application of TBL in three mid-sized sections of linear algebra in the 2012-2013 school year. Linear algebra at my institution is a sophomorelevel course aimed primarily at students who major in mathematics (about $15 \%$ of the students in the course), computer science, and various engineering disciplines, although many other STEM majors take the course as well. The course is generally taught as a skills-based course with a grounding in mathematical theory. I decided on this course for my first test run of TBL for two reasons. First, the methods of TBL seemed appropriate to the mix of skills and theory inherent in the course syllabus. My introduction to TBL led me to believe that the approach would be most effective in courses where there was a lot of room for discussion of the content, instead of courses based entirely on development and practice of skills. Second, the classroom size, 55-60 students, did not seem like too much to handle on a first attempt. This is a decision based entirely on my own comfort level as a first-time adopter of an active learning pedagogy.

In this paper, I first explain the usual format for TBL, and then discuss the modifications that I felt were needed for the mathematics classroom. I then discuss the results from the first year of TBL use, comparing these results to previous sections of the same class, in which I had used a standard lecture approach.

\section{Empirical controls}

Before presenting TBL and its modifications, I will present a digest of the methods I used in linear algebra courses previous to my exposure to TBL. The main feature of these courses was the lecture. Classes would meet two or three times a week, for a total of 150 minutes weekly. Almost all class time would consist of lecture. Although students were encouraged to read the course text before class, in reality this lecture would be the first exposure to course material for most students. Lectures, therefore, would closely follow the presentation of material given in the book, generally with additional explanation and examples. Students were given weekly homework assignments consisting of problems taken from the text, and the course would be punctuated approximately every other week with an in-class quiz or examination. Students would be tutored on an individual basis, at their request, during office hours outside of class. Most readers will find this model to be a fairly standard treatment of the mathematics classroom.

Standard, also, is the student reaction and learning outcomes, given this pedagogical approach. Students were generally bored or sleepy in class (even given that I have histor- 
ically been thought of as a very good and highly rated lecturer). With a few exceptions, students would often be non-participatory in class despite prompting for discussion, questions, and so on. Learning outcomes were uninspiring; the proportion of the class that could be expected to pass with a grade of ' $\mathrm{C}$ ' or better was usually $60 \%-70 \%$ of the total student population, or worse (see Section 5). These sorts of results are typical at my university across all core mathematics courses at the 100-level and 200-level.

It should be noted that even with the adoption of active learning techniques in the classroom as detailed below, there still persists a basic cycle of information exposure - homework - tutorial throughout the course. Under traditional methods, information exposure generally takes place in the classroom, homework takes place at home, and tutorial takes place at the student's option. Under active learning approaches, information exposure can be partially moved outside of the classroom, making room for more tutorial inside the classroom, and in particular, forcing the student to undergo more tutorial than they might otherwise elect. That being said, although it is not a focus in the discussion below, even under TBL students still have weekly homework assignments, and still have the option to attend extra tutoring sessions outside of the classroom.

\section{Team-based learning}

The standard approach to TBL consists of four components: persistent teams that last throughout the term; a readiness assurance process (RAP) that ensures that students have their initial exposure to course material outside of class time; team application activities that follow the 'Four S's' (see below); and a peer review process to help ensure that team members work together effectively. The interplay of these four components creates a positive and active classroom environment in which students work together to succeed in course goals and improve themselves as learners.

The first component is persistent teams. According to the TBL literature ([8], [9], for instance), each team should consist of between five and seven students. Teams should be sized large enough to accomplish significant tasks that would be taxing for individuals. At the same time, teams should not be so large that they naturally split into subgroups or cliques within teams. Teams should also persist throughout the term, to maximize the development of synergy within each team. The research shows that a team takes as much as 15-25 hours of contact time to 'gel' and learn to work as a unit. Since TBL teams are only required to meet in the classroom itself, it can take as much as half the term for team members to learn to work well together. Finally, teams should be created in a way that ensures as much as possible that each team will have students of varying backgrounds, abilities, experience levels, and areas of interest.

The second component is called the RAP. The course is divided into several units of course material, usually about two or three weeks long for each unit. For each unit, students begin by reading relevant texts and materials outside of class. The students then take an individual readiness assessment test (iRAT), which is generally a multiple choice quiz on the reading. This is done before the material has been presented in class. The iRAT is followed by a team readiness assessment test (tRAT), which is the same exact quiz, only taken in teams instead of individually. The tRAT should have immediate feedback so that students will know whether or not they are understanding the material. After taking the tRAT, teams are given the opportunity to appeal missed questions that the teams feel were missed due to ambiguity in the question design instead of misunderstanding on the students' part. The difficulty of questions on the RAP should be enough to force the student to engage with the material on some level, but should not represent mastery of the concepts involved. The RAP should be followed up with short clarifying lectures. 


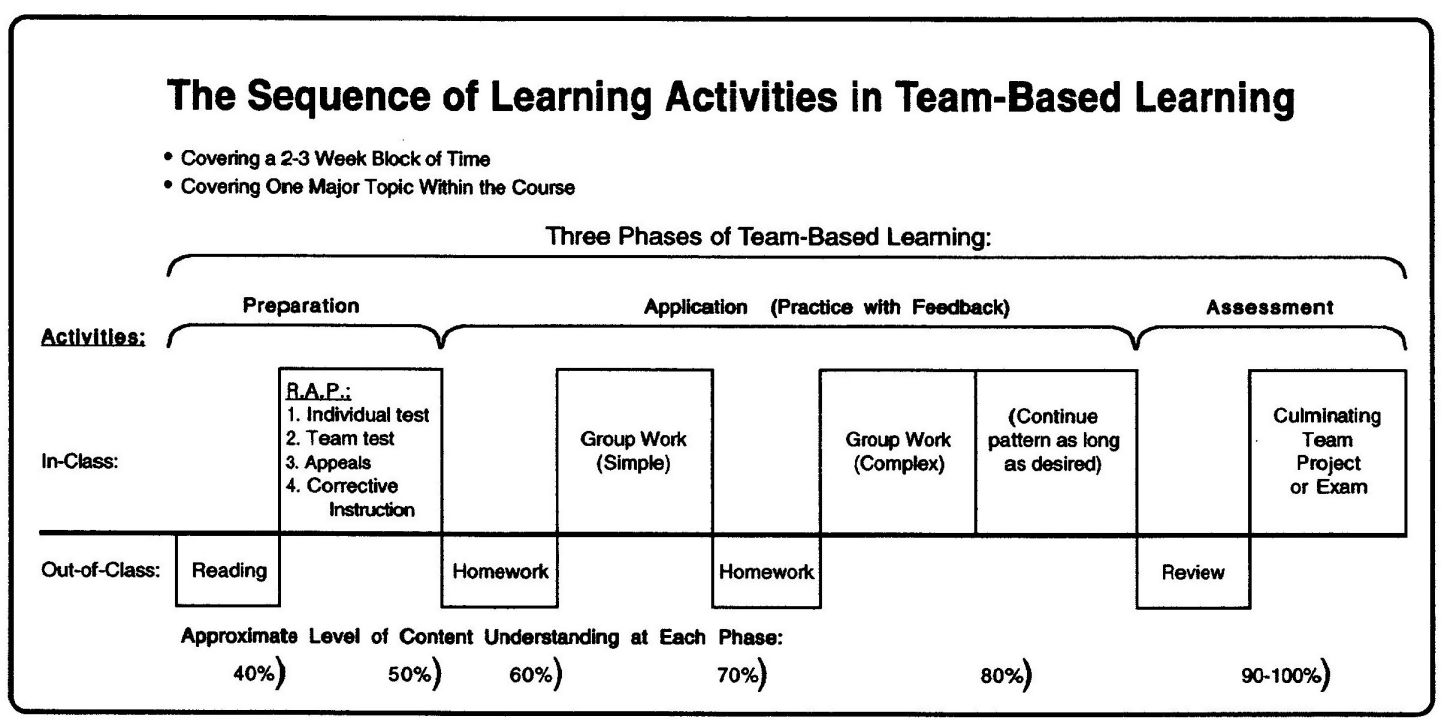

Figure 1. From [8], p. 11

The bulk of class time is spent in the third component of TBL, team application activities. The teams are presented with various tasks, and work on these tasks together in class. Well-designed activities should follow the 'Four S's': (1) Significant problem: activities should give teams the opportunity to use course concepts in a significant way, both in degree and meaning. (2) Specific choice: team activities work best when they culminate in a discrete choice of a course of action. For instance, a team could be given a medical case study in which they must select the best course of action for treatment of a patient, choosing from a list of plausible choices. (3) Same problem: teams should each be given the same activity to work on. Different teams should not have different tasks. (4) Simultaneous reporting: teams should all report on their results at the same time. The last two points are to ensure that all teams remain engaged at all times. Students will be more interested in reviewing activities that they have personally worked on.

Although it is not a specific component of TBL, each unit of material will generally culminate in some sort of quiz or examination. Whether these will be given individually or in teams will depend on the instructor and the course goals. This structure is designed so that for each unit of material, students will alternate between working at home and in class, until concept mastery is achieved. Students are first exposed to concepts in reading. Then they engage with the material through the RAP process. At home, they work on assigned homework exercises. They then go to class and have further team activities. After further home study, they are given an in-class examination. This tiered system ensures that students have a balanced schedule of study at home and active learning in the classroom (see Figure 1).

Common student complaints about teamwork tend to focus on the idea that different team members may contribute disparately to the team. Often, students feel as though some members generally lead their teams and teach everybody else, while other members might slack off or not even show up regularly to class. These complaints are mitigated by the fourth major component of TBL, peer review. Each student has the opportunity at the end of the term to rate his or her teammates on their individual level of contribution to the team. These reviews affect team members' grades in some significant fashion. This process ensures that a student's performance (or lack thereof) in the group influences their grade in a significant way. In effect, the peer pressure created by this situation can do what even the most dedicated instructors cannot do directly: encourage weak students to work harder. 


\section{Adaptations}

While TBL sounds great on paper, it faces significant challenges for use in the mathematics classroom. Chief among these obstructions is the fact that the course material for most mathematics classes does not lend itself to division into two- or three-week long units. Mathematics students simply cannot be expected to front-load their reading in that manner. Usually, the material learned on day two relies heavily on a working understanding of the material learned on day one. Therefore, more frequent RAPs become necessary - but of course, this change heavily informs the rest of the course design. Below, I detail the major adaptations that were necessary in order to use TBL for my linear algebra courses.

As stated above, the first and the most major change was the need for more frequent RAPs. In Fall 2012, the course met twice a week, and each meeting was 75 minutes long. We had a team quiz or individual test approximately once every two weeks. On every day that there was not a quiz or test, we started with a RAP. Therefore, the class schedule ran as follows. For almost every class meeting, students were responsible for a reading, generally one section of the text (occasionally two). Each reading was followed by an individual Readiness Assessment Test (iRAT). Each iRAT consisted of five multiple choice questions that were administered online. The iRAT was due two hours before class, so that the student would have ample time to digest the material before class. Students were given only one attempt on iRATs and were not provided with score feedback, as this would defeat the purpose of the team Readiness Assessment Test (tRAT). Upon coming to class, students would sit in teams and be given the same five question quiz as a tRAT. Students were allowed to bring in iRAT scratch work to try to make their cases for various answers to their teammates. Each question was worth four points; teams were allowed to 'wager' points on various answers if they were unsure of the correct answer.

As iRATs were done before class, they did not act as a drain on contact time. tRATs would usually take up approximately the first 10 minutes of each class session. The remaining class time was an organic mixture of tRAT answer review and application activities. The tRAT would be used as a launching board for discussion of concepts from the reading. Short clarifying lectures were given as necessary - teams were given an opportunity to ask for clarifying lectures on their tRAT submission sheets. As related problems and skills came up, teams were given activities that they could work on for a few minutes so that they would have in-class exposure to difficult issues that were not evident from the reading. Therefore, that teams could report simultaneously on tRAT answers and team activities; each team was given five large coloured cards printed with the letters A through E. In any multiple choice situation, each team could hold up their card when given a signal. The array of answers for a given question could often be used as a start point for a discussion of the question.

As the course structure emphasized the RAP component of TBL, it was necessary to downplay parts of the 'Four S' team activities, in the following sense. As linear algebra is at heart a skill course, it was difficult to design activities that represented significant problems. In fact, I often found an opposite approach to be more effective. I would often present, as a team activity, a typical mathematical challenge, as could be expected on homework or a test. I would then split the question into a few discrete parts. Part one would generally be to determine what needed to be done to solve the problem. Part two would be to run the corresponding calculations. Finally, part three would be for each team to analyse its results to give a solution. While this approach did not allow teams to tackle problems that were larger in scope than an individual could be expected to do in class, it did still provide active engagement for students. It was, of course, not always possible with this approach to provide teams with a specific choice of action, as team 
activities would often consist of a math problem considered for its own sake, not for application to some conundrum. Still, I held to the tenets that teams should always work on the same problem as each other, and report simultaneously on their work. It is also worth noting that while these were not often appropriate in my linear algebra course, many math instructors could use the tenet of 'significant problems', in that almost any word or story problem (as would be used, for instance, in introductory calculus courses) is essentially a real or significant problem.

As the scope of team activities was not as large as in standard TBL, it was also necessary to decrease team sizes. Five to seven students would be too unwieldy for the linear algebra classroom. Instead, teams started at four members each. After late course adds and drops in the first two weeks of the term, teams stabilized generally between three and four members each, with rare teams of five. These team sizes seemed appropriate for the types of team activities in the course. In order to form teams on the first day of class, students were lined up in the hallway by major, and then they counted off into teams. Therefore, each team ended up with a wide array of areas of interest, and along with that, a wide array of mathematical ability and proclivity. This particular team size allowed another fun classroom technique: each team corresponded to a rank in a deck of cards (Jacks, Aces, Twos, etc.), and each individual corresponded to a suit. Therefore, I could draw a card from a deck to call on a random person. Since anyone could be called on to explain a problem, teams took pains to make sure that all of their members could explain their activity responses, to try to make sure that the team would not look bad and lose face in front of the class. Students also appreciated the fact that I myself was also represented in the deck of cards, as the joker, and could be called upon randomly just like anybody else. (Although random calling is very much in the spirit of TBL, the use of playing cards is a personal trick I learned at an unrelated teaching and learning conference.)

Grading was handled in relatively standard TBL style. Each student's overall grade was split into two major components: the individual grade and the team grade. Individual grades were composed of scores on homework, iRATs, individual examinations, and the (individually administered) final examination. Team grades consisted of tRATs and team quizzes. Each team was allowed to choose what relative weights their individual and team scores would have in their overall grade. The team component was allowed to count for $15 \%, 20 \%, 25 \%$, or $30 \%$ overall. Finally, each student rated his or her teammates in the following fashion. Each person on a four-person team was given 29 points to distribute to his or her teammates (19 points for a three-person team). Students did not rate themselves; therefore, they had an uneven number of points, averaging about 10, to distribute to their teammates. Each student's average rating was reweighted so as not to bias for number of team members, and then was used to weight his or her overall team score. So, for instance, if a student had been rated by his or her team members to have an average score of 8 out of 10, his or her team score would be multiplied by $80 \%$ before being factored into his or her overall grade.

\section{Results}

The results in my inaugural uses of TBL were striking on many levels. I will discuss the changes in classroom attitudes, the changes in overall grades, and the changes in student performance. The comparison below is between five different sections of linear algebra, all taught by me: Fall 2011 and Spring 2012, taught with traditional methods, and then Fall 2012 and two sections in Spring 2013. Fall 2012 and Spring 2013 are the 'test classes' in which I first used TBL, with methods as described above in Section 3. Fall 2011 and Spring 2012 act here as empirical controls. Both control classes were 
taught using traditional lectures as detailed above under Section 2, with various methods of homework collection, quizzes, and tests. All work submitted was done by individuals. There was no teamwork in any official capacity, and little student involvement during class time.

Further notes on comparability: all homework assignments were constant between terms, and tests were of comparable difficulty between terms, with approximately onethird of the points available on each examination going towards solid theory-based questions, and the rest of the points for more skill-based questions. The course covered approximately the same material each term, although two extra sections of the text were covered in Fall 2011. In Spring 2012 and all TBL terms, students were given the opportunity to earn extra credit up to the value of a single homework assignment by reading and doing homework exercises on those two extra sections.

The first and the most immediately noticeable change was the qualitative change in classroom attitudes. Although I expected resistance from the students to the strange new teaching techniques to which they were being subjected, such difficulties never materialized. Students were quick to buy into the idea of TBL, largely due to careful reinforcement of the message that TBL was based on research, and that these classroom methods were being adopted with the students' learning outcomes in mind. It should be noted that as active learning techniques have not found a large foothold at my institution, these pedagogical approaches were entirely new for the grand majority of my students. In the student feedback comments at the end of the term, only one student out of the 168 in the treatment group complained about the nature of TBL (although, it should be noted that this student did complain vehemently that I never taught him anything - an interesting look into some of his implicit assumptions about teaching and learning). It was easy to dismiss this complaint in light of its rarity, and the fact that this student passed the class. Even some of the rare students who failed or withdrew told me in personal discussions that this failure stemmed from their own disengagement from the class, usually due to outside factors. In fact, most of them enjoyed the class, and seemed to think that they had done better under TBL than they would have in other circumstances (see the discussion of grades, below).

In general, students in the TBL courses were engaged in classwork and had positive attitudes towards the class and the course material. This should be contrasted with the control courses, especially Fall 2011, in which students did not participate and seemed generally bored. Students in the TBL course clearly enjoyed the class and developed some positive learning habits as a result of the course structure.

One could ask about the attitudinal effects of TBL on those students who do not flourish in group work situations. First, the professionals that these students will become will not work in a vacuum; students must develop the skills necessary to work well in collaborative situations in order to become competitive in today's economy. I feel that it is important for us, as educators, to strive towards such long-term educational goals for our students. Secondly, somewhat surprisingly, and counter to my expectations before using TBL, I have yet to actually observe such a student - or, at least, one who persisted in this view for the entire term. Many students think that they work better alone, and I always hear concerns from students (especially at the upper end of the performance spectrum) who are convinced that working with a team will hamper them. These complaints always dry up after a few weeks into the term, once the teams start to cohere and learn how to work together. Usually, the most vocal complainants at the beginning of the term become the most vocal celebrants of TBL once they experience how effective it is. It is very gratifying as an instructor to hear from a previous student about the wonderful study group they have formed, when once that student thought they worked the best alone. This has been a common occurrence under TBL. 


\begin{tabular}{|c|c|c|c|c|c|c|c|}
\hline Term & No. of Students $A$ & B & C & D & $\mathbf{F}$ & W & DFW \\
\hline Fall 2011 & $376(16.22 \%)$ & $9(24.32 \%)$ & $2(5.41 \%)$ & $4(10.81 \%)$ & $7(18.92 \%)$ & $9(24.32 \%)$ & $20(54.05 \%)$ \\
\hline Spring 2012 & $5614(25.00 \%)$ & $7(12.50 \%)$ & $12(21.43 \%)$ & $4(7.14 \%)$ & $12(21.43 \%)$ & $7(12.50 \%)$ & $23(41.07 \%)$ \\
\hline Fall 2012 (TBL) & $5719(33.33 \%)$ & $19(33.33 \%)$ & $13(22.81 \%)$ & $2(3.51 \%)$ & $0(0.00 \%)$ & $4(7.02 \%)$ & $6(10.53 \%)$ \\
\hline Sp 20131 (TBL) & $5328(52.83 \%)$ & $14(26.42 \%)$ & $6(11.32 \%)$ & $0(0.00 \%)$ & $0(0.00 \%)$ & $5(9.43 \%)$ & $5(9.43 \%)$ \\
\hline Sp 20132 (TBL) & $5821(36.21 \%)$ & $19(32.76 \%)$ & $12(20.69 \%)$ & $1(1.72 \%)$ & $1(1.72 \%)$ & $4(6.90 \%)$ & $6(10.34 \%)$ \\
\hline
\end{tabular}

Figure 2. Raw grade data

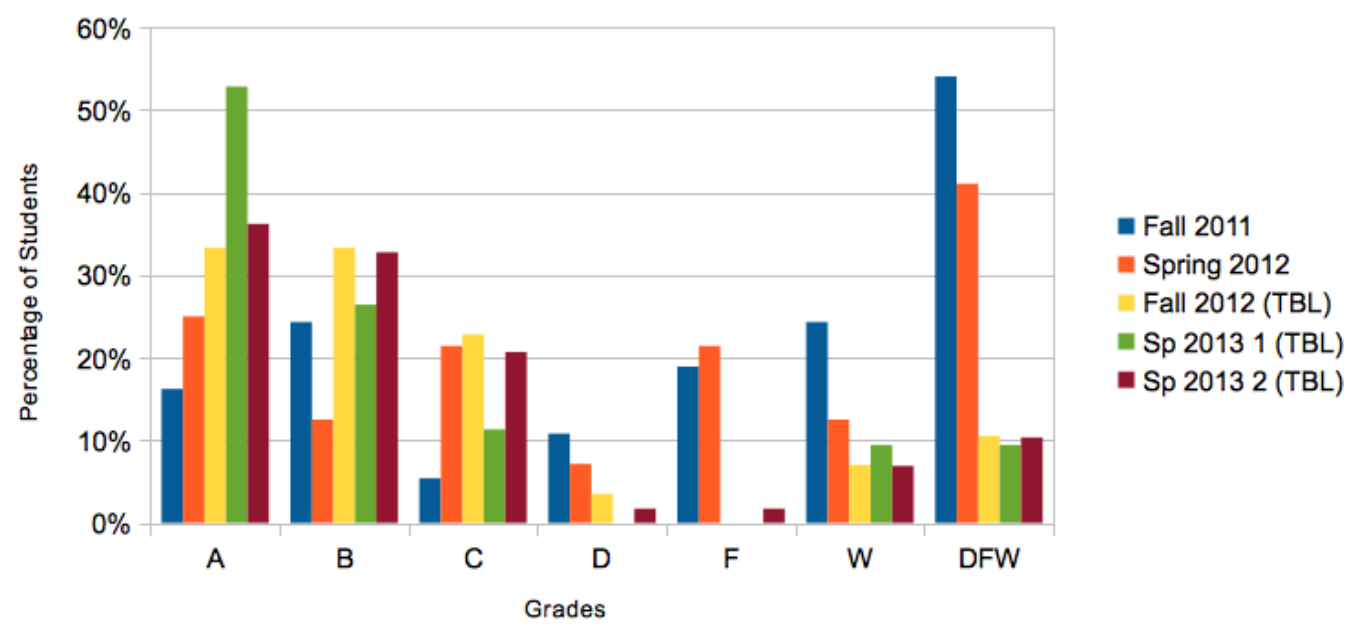

Figure 3. Comparison of percentages of grades earned

It should also be noted that from my point of view, the course was a lot more enjoyable than a traditional lecture course. Instead of lecturing - essentially reading a book to the students for two and a half hours a week - class time became a fun and engaging block of time. Instead of a thick sheaf of lecture notes, the instructional preparation amounted to a short list of highlights from each section of the text. Classes were much more fluid and open than a traditional lecture. Although much more time had to be taken outside of class (mostly for the writing of RAPs), this material only has to be developed for the first use of TBL in a given course. After that, it is available for future terms.

The second and most gratifying difference was the change in grades. A word, first, on grades and grade assignment methods. Firstly, I do not have access to records of students who dropped in the first two weeks of the course without a ' $\mathrm{W}$ ' grade on their transcript. Therefore, all grade analyses are based on the student population who remained enrolled after the late add deadline for each term (approximately two weeks into each term) - that is, based on the students who at least intended to give a fair effort to their linear algebra class. Secondly, a 'C' grade is required at our institution in order for the class to fulfil any concentration requirements (course requirements for a student's major). Therefore, failure rates that I will refer to are the same as the 'DFW rates', that being the percentage of students who earned a ' $\mathrm{D}$ ', an ' $\mathrm{F}$ ' (failure), or a 'W' (late withdrawal) in the course. Finally, grades were generally assigned on approximately the standard scale of $90 \%=\mathrm{A}$, $80 \%=\mathrm{B}, 70 \%=\mathrm{C}, 60 \%=\mathrm{D}$, and an $\mathrm{F}$ for scores below $60 \%$. There are no plus- or minus modifiers given to letter grades at our institution.

Grade information is shown in Figures 2 and 3. Figure 2 shows a chart of the raw data - how many students earned each grade in each class. Figure 3 shows this information as a bar graph, showing the percentage of students that earned each grade in each class (therefore controlling for the number of students in each class). It is evident that grades were very low in Fall 2011. In particular, the failure rate is an extremely high $54.05 \%$. Spring 2012 is largely representative of the sort of grades that are generally seen in 100- 


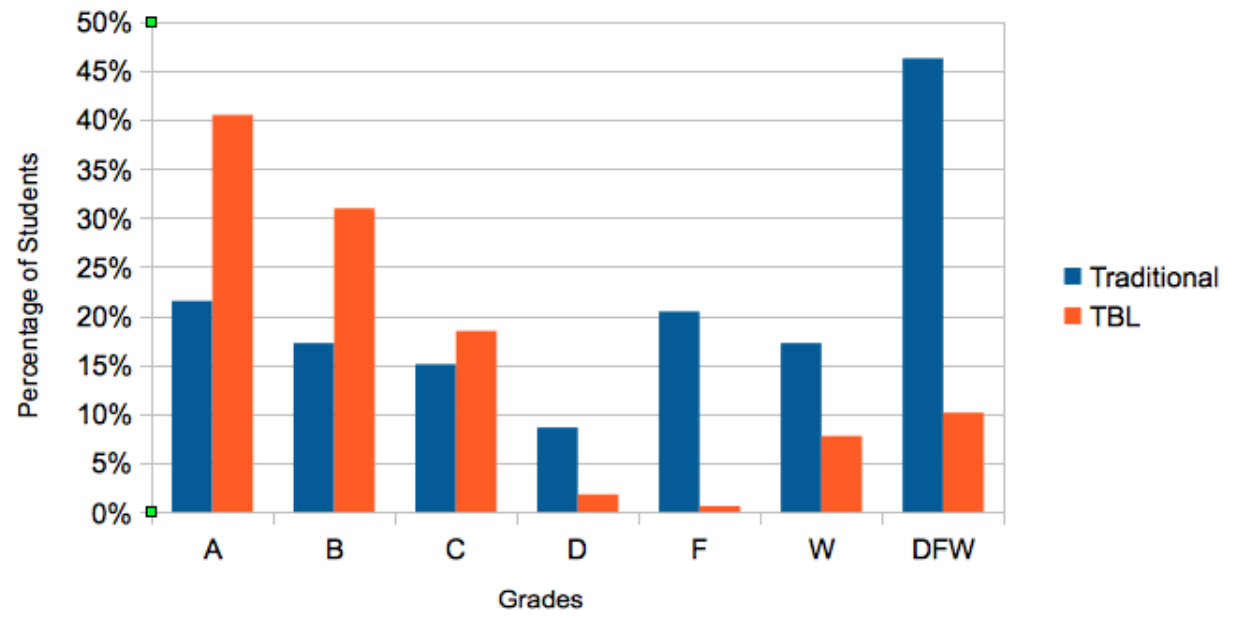

Figure 4. Comparison of grades between teaching methods

level and 200-level mathematics courses at our institution. The failure rate is $41.07 \%$, which is common for these courses.

The grades earned in Fall 2012 with the use of TBL are a revelation. A third of the class earned A's, and another third earned B's. Two students received D's, and four withdrew. Nobody failed. The DFW rate was an unheard-of $10.53 \%$. It is worth noting that one of the two D grades refused to do any homework or iRATs throughout the term, and still earned a very low $\mathrm{C}$ on the final examination (a different student from the vehement complainant mentioned above).

These trends continued in the two sections of linear algebra that I taught using TBL in Spring 2013. An extraordinary half of the class in Spring 2013 (Section 1) earned an A. Compare this with the half of the class that got a D, F, or W in Fall 2011. Section 2 had comparable grades overall to the Fall 2012 class. DFW rates were $9.43 \%$ for Section 1 , and $10.34 \%$ for Section 2 .

A simplified graph is provided in Figure 4, specifically contrasting the two teaching methods. It shows the overall percentage of each grade earned across the traditional sections of linear algebra (Fall 2011 and Spring 2012), and across the TBL sections of linear algebra (Fall 2012 and both sections of Spring 2013).

It would be easy enough to dismiss these grade improvements as an artefact of the strong influence of the team portion of the students' overall grades, were it not for the corresponding increase in performance on the final examination, which can be taken as evidence for general student performance increases in the course. The data is shown in Figures 5 and 6. Letter grades represent the standard $90 \%-80 \%-70 \%$ breakdown, with an $\mathrm{F}$ representing a score of less than $60 \%$ on the final examination.

In the control terms (Fall 2011 and Spring 2012), scores on the final are grouped relatively evenly across all categories. Both terms have a non-trivial number of students who were enrolled for the entire term but did not attempt the final examination. In the TBL terms (Fall 2012 and Spring 2013), these observations no longer hold. Everybody attempted the final, and scores on the final were heavily stacked towards higher results. When performance on the final is compared between the different classes, there are no significant differences in performance between the two control terms. The TBL terms, however, show large gains in overall performance, and a much tighter spread of data. In particular, when looking at the data for all students who were enrolled at the time of the final, there is an incredible $20 \%$ gain (approximately) on the mean final score between 


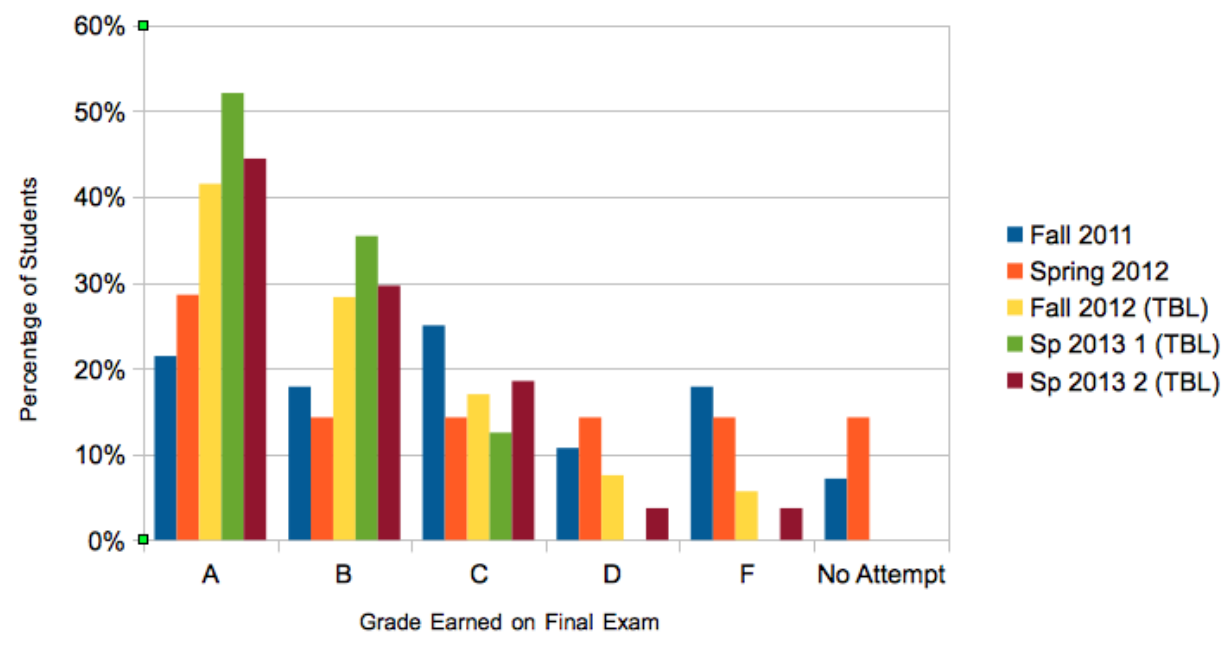

Figure 5. Comparison of scores on final examinations

\begin{tabular}{|l|r|r|r|r|r|r|}
\hline & \multicolumn{3}{|c|}{ Data for All Enrolled Students } & \multicolumn{2}{c|}{ Data for Students who Attempted the Final } \\
\hline Term & Median & Mean & Standard Deviation & Median & Mean & Standard Deviation \\
\hline Fall 2011 & $78.00 \%$ & $67.86 \%$ & $28.56 \%$ & $78.50 \%$ & $73.08 \%$ & $22.29 \%$ \\
\hline Spring 2012 & $77.50 \%$ & $66.41 \%$ & $32.49 \%$ & $79.75 \%$ & $77.48 \%$ & $19.35 \%$ \\
\hline Fall 2012 (TBL) & $86.50 \%$ & $84.85 \%$ & $14.42 \%$ & $86.50 \%$ & $84.45 \%$ & $14.42 \%$ \\
\hline Sp 2013 1(TBL) & $89.50 \%$ & $90.21 \%$ & $8.60 \%$ & $89.50 \%$ & $90.21 \%$ & $8.60 \%$ \\
\hline Sp 2013 2 (TBL) & $88.75 \%$ & $86.81 \%$ & $14.02 \%$ & $88.75 \%$ & $86.81 \%$ & $14.02 \%$ \\
\hline
\end{tabular}

Figure 6. Statistical data on final examinations

control and test terms.

We provide below in Figure 7, a simplified graph that contrasts the scores on the final examinations between the two teaching methods.

I should address the question of the 'testing effect' - that with the addition under TBL of such a large number of iRATs and tRATs to the course, students are tested much more often, and that therefore the entire pedagogy could be interpreted as 'teaching to the test'. This is, of course, a valid concern. My answer to this point is that the style of questions on

iRATs and tRATs is radically different from those on quizzes and examinations. iRATs

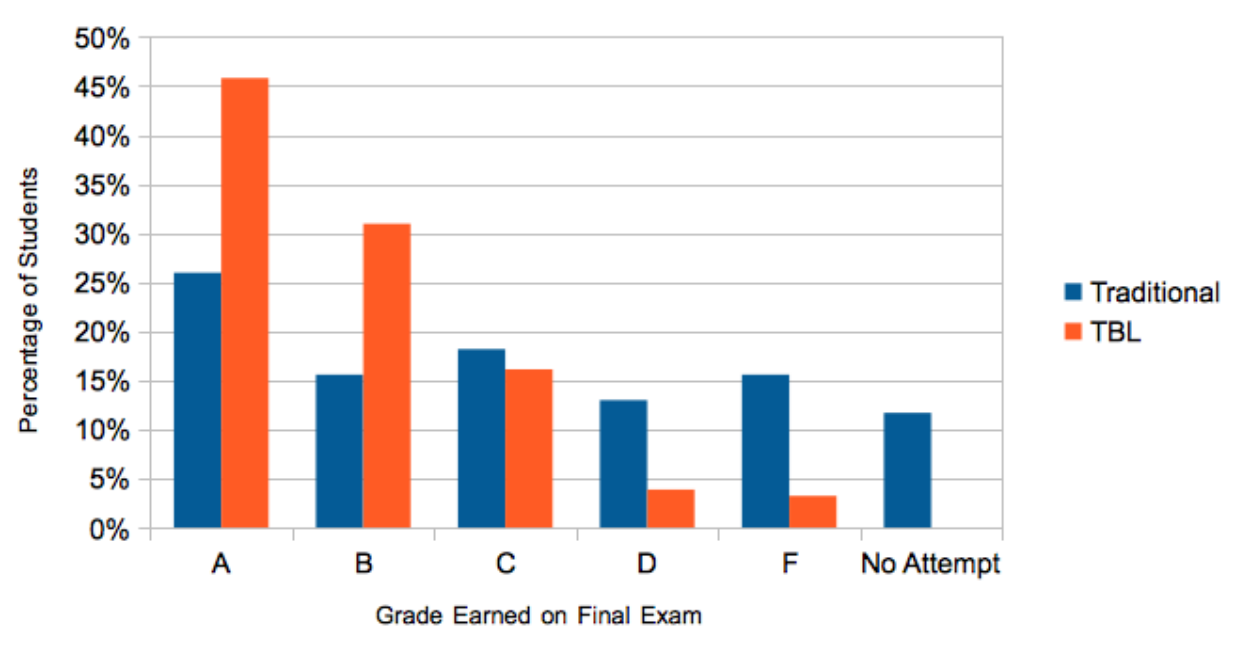

Figure 7. Comparison of finals scores between teaching methods 
and tRATs are meant to enforce student reading before class. Questions on these tests are not examination-level questions. Instead, they are just difficult enough to force students to engage with the reading. (Preparing these questions is actually, for me, one of the most difficult parts of a TBL course to prepare correctly, and success in such a course rests heavily on structuring these questions correctly.) Questions on quizzes and examinations are asked after students have been through one or more cycles of homework on any given subject; therefore, these questions can be much more nuanced and in-depth than earlier questions. Therefore, my belief is that test scores under TBL are improved not because students have been asked examination-style questions more often than under a lecturebased approach. Instead, I believe that the improvement on test scores is caused by the fact that the course design under TBL forces the students to engage with the material more heavily, more often, and with more care than under traditional teaching methods.

Statistical tests on the effect of TBL on student performance return results as follows. First, a Welch twosample $t$-test between scores on the final examinations in control terms (Fall 2011 and Spring 2012) and final examination scores in TBL terms (Fall 2012 and Spring 2013) reports a highly statistically significant change. $t$ is equal to -4.3795 , and $d . f .=131.148$, with an extremely small $p$-value of $2.411 \times 10^{-5}$. The TBL finals have a mean that is higher by a value whose $95 \%$ confidence interval is [20.93328, 55.42387] out of 200 points. A Pearson Chi-squared test for goodness of fit for the TBL letter grade distribution versus the non-TBL letter grade distribution gives $\chi^{2}=98.037, d . f .=5$, and a vanishingly small $p$-value of less than $2.2 \times 10^{-16}$. Clearly, the results of the use of TBL in these classes have produced extremely statistically significant results.

\section{Conclusions}

Clearly, careful use of TBL in mathematics classrooms can improve test performance and grades. In addition, many students had positive comments about the overall experience, and expounded on how they had improved their skills in studying and reading a mathematics text. To quote from a student course evaluation in Fall 2012: 'The best part of the course was the iRATs. I learn most effectively when I read the text, so being forced to read helped me master the material'. Another student claimed that 'The team-based learning was effective. A lot of times if one of us didn't know about a topic, one of the others did. It forced us to create study groups where we may not have if it was a regular class.' Finally, 'Using the iRAT/tRAT approach was effective at getting exposure to the topics before class and getting any questions explained in lecture.'

In addition, I have heard anecdotal evidence that TBL was useful to my students after my class was over. I spoke to one student two months after her TBL course had ended. She told me that she had retained the habit of reading her math textbook before class, and that it was making her next math class much easier to handle. As mentioned above, I have heard from many students who learned to develop and work with study groups from my TBL course, and have continued to do so in later classes. I have also started to hear from other instructors that my former students liked my TBL course and want TBL to be used in their other math courses.

Going forward, my next large research goal will be to adapt TBL for use in large (100+) mathematics lectures. It will be interesting to see what adaptations will be necessary in order to retain the effectiveness of TBL in larger courses. 


\section{Acknowledgements}

Special thanks goes to Sarah Leupen, who introduced me to TBL and has been indispensable as a guide. Thanks also to Samantha Prins for allowing me to adapt her techniques from her Statistics course, and to Linda Hodges for general guidance, support, and editing.

\section{References}

[1] Birk JP, Foster J. The importance of lecture in general chemistry course performance. Journal of chemical education. 1993;70(3):180.

[2] Crouch CH, Mazur E. Peer instruction: Ten years of experience and results. American Journal of Physics. 2001;69:970-977.

[3] Deslauriers L, Schelew E, Wieman C. Improved learning in a large-enrollment physics class. Science. 2011;332(6031):862-864.

[4] Knight JK, Wood WB. Teaching more by lecturing less. Cell Biology Education. 2005; 4(4):298-310.

[5] Prince M. Does active learning work? A review of the research. Journal of engineering education. 2004;93(3):223-231.

[6] Bode M, Drane D, Kolikant YBD, Schuller M. A clicker approach to teaching calculus. Notices of the AMS. 2009;56(2):253-256.

[7] Park K, Travers KJ. A comparative study of a computer-based and a standard college firstyear calculus course. CBMS Issues in Mathematics Education. 1996;6:155-176.

[8] Michaelsen LK, Knight AB, Fink LD. Team-based learning: A transformative use of small groups. Greenwood Publishing Group. 2002.

[9] Team-based learning collaborative. http://www.teambasedlearning.org. 2014. 